\title{
Research on the "Shape" Design Method of Museum Exhibition Space under the Background of New Media Art
}

\author{
Kai Cao, Chunmei Wei, Qiannan Liang \\ School of Art and Design, Wuhan Textile University, Wuhan, China
}

\begin{abstract}
Traditional museum space design is generally limited to cost and engineering volume, and follows the conventional unified design process of large-scale space fixtures, isolating the design contents of space hard decoration and internal soft decoration and display, and even flood lighting intelligence, lacking unified overall consideration and response. The disjointed design in the early stage led to a large number of space contradictions in the exhibition placement and actual use and operation after the completion of the hard installation and delivery. The intervention of new media art changes the traditional exhibition form. At the same time, the traditional public space design process also begins to change because the exhibition activity of new media art forms has many requirements such as technology, process, material, sound and light, and even environmental psychological effect on the space form and scale. Based on case studies of different characteristics, this paper summarizes the systematic design methods of new media art's involvement in the hard installation of museum exhibition space from three dimensions of spatial layout, spatial form and spatial scope.
\end{abstract}

Keywords: New Media Art; Exhibition Space Design; Spatial Layout; Space Form; Space.

\section{Introduction}

With the advent of the information age in the 21 st century, the emerging new media art with advanced technical means caters to the contemporary aesthetic trend and gradually infiltrates into the field of museum exhibition space design. The digital characteristics of new media art perfectly match the goal of virtual digital development of museums. The development of VR experience technology, AR naked eye holographic projection technology and artificial intelligence interaction technology promotes the diversification of museum exhibition activities and the transformation of efficient information transmission, and puts forward new requirements for the preliminary design and implementation of museum exhibition space [1]. Therefore, this paper focuses on how to cooperate with the exhibition space of contemporary museums and the exhibition art of new media, and how to give full play to the rich exhibition effect of new media art to further build the indoor exhibition space of museums with sufficient experience, strong interest, fast communication and high artistic quality $[2]$.

\section{New Media Art}

New media is an environment in which everything is media, and it is an update of the previous media. As for new media art, it refers to the artistic form with digital technology as the core, interaction as the basic feature, and the use of computer, network and other latest scientific and technological achievements as the creation media. Audiences can connect to digital works through five senses and then interact with them, thus achieving an art form of immersion, experience and emotional resonance [3].

\section{Museum Exhibition Space Development Status}

\subsection{Strengthening of Social Significance}

In the context of information explosion in modern society, museums, as the concentrated embodiment of human social civilization and historical information, have profound cultural deposits and research value, but also serve to meet the public's increasing scientific and cultural knowledge 
needs of the "urban living room", with practical spiritual needs and development prospects [4]. Issued by the State Council on May 11, 2021, the "guidance on promote reform and development of the museum" clearly put forward "in China museum in venue construction, protection of cultural relics, collection, research, display exhibition, open service, education, communication, international communication, the new progress of increasingly become the focus of world museum development and hot spots. At the same time, however, it should be noted that the contradiction between the unbalanced and inadequate development of museums and the needs of the people for a better life is still prominent, and the development orientation, system layout, function and system mechanism need to be improved.To deepen the reform and continuously promote the high-quality development of China's Museums" [5].

Under the background of this era, China's museum system has been optimized year by year. Under the general trend, the construction of museums with increasing quality has become the first step in the vigorous development of social and cultural undertakings. Since the 13th Five-Year Plan, the number of museums in China has increased rapidly year by year. From 2010 to 2020, 5,788 museums of different sizes have been registered in China (Figure 1).

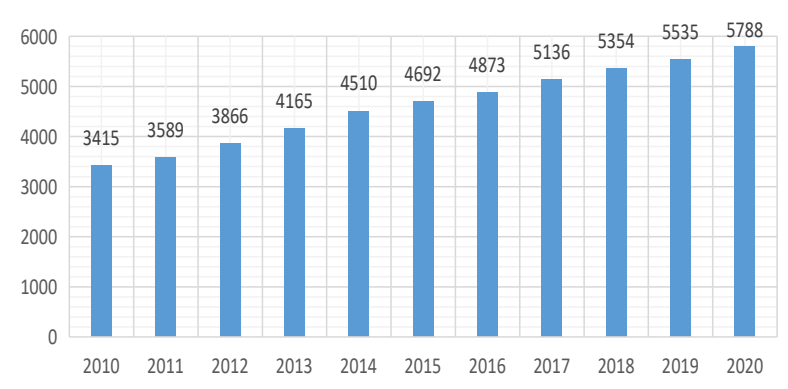

Fig 1. Trends in the number of Chinese museums from 2010 to 2020

\subsection{Traditional Design Lag}

At present, a large part of traditional museums in China separates the architectural construction from the internal exhibition design, or generally regard the building as the neutral container of museum exhibits, resulting in the uniformity of exhibition forms in all museums [6]. In the form of traditional museum ZhanChen homogeneity, not used for different display content and theme of rationality ZhanChen form and display method, the early stage of the building interior space design also without considering the linkage and ZhanChen activity, repetitive physical display attract the public's aesthetic fatigue, appeal gradually reduce, can't reflect exhibits unique thematic characteristics, This runs counter to China's original intention of promoting the growing prosperity of cultural undertakings through museum construction.Although all the museums in China have been built with "charm and elegance", the stereotypical exhibition forms also cause the rare treasures in the museums to be covered with dust.

The public demand for science and culture and art of spiritual civilization in deepening, hope get more intrinsic cultural value increase, while lack of traditional museum in ZhanChen activity and interaction with the exchange of tourists, tourists unfamiliar distance, lack enough exploratory and desire, which is unfavorable to further excavations information publicity and cognition.Therefore, based on the above situation, as information bearing and exhibition space, museums in China also need to carry out the innovation of modern information technology [7].

\section{The Museum Displays the "Shape" Design Methods of Space}

\subsection{Dynamic Spatial Layout with Active Sharing is Adopted as a Whole}

Generally confined to the traditional museum exhibits protective collection, USES the real static display form, and with the visitors is set between absolute security distance limit, so visitors tour 
route general relatively fixed and single, divided into fixed on dimensional layout of tourist activity space reserves with the exhibition space, form form is monotonous, layout ZhanChen convergence of museum space.The rigid space layout of the museum also restrains tourists' experience behavior in the exhibition environment. With low participation of tourists, the feedback of the exhibition information will be greatly reduced, and the contents of the visit will be forgotten in a short time, which is not conducive to the commercial promotion and cultural promotion of the museum. The application of new media art in exhibition activities has fundamentally changed the organizational logic and experience needs of exhibition space, and the layout pattern of space has also changed with the change of target needs, in order to inspire and guide tourists to resonate with and deeply understand the exhibition information in the harmonious organization of space and exhibition form[8].

\subsubsection{Build the Plane Layout of Centripetal Gathering}

Sommer, a psychologist, proposed the concept of Sociopetal space by observing the correlation between the frequency of patients' mutual communication and the positive and negative orientation of the seats in a hospital. It refers to a public space that can lead the public to gather actively and then have related activities through organizational layout [9]. Under the influence of new media art, museum exhibition space has gradually changed from the niche of private collection to the public of general cognition, focusing more on attracting people to have more communication and information sharing. This functional demand promotes the development of exhibition space into a centralized organizational layout.

Traditional museum ZhanChen space generally is based on the partition type "layout is given priority to, divide the theme of the exhibition hall or exhibits, will separate between tourists and weaken the engagement of tourists, the full experience of visiting a participant is the indispensable part of the chain, lack of engagement leads to tourists can't really enter into the state of the immersive experience (Figure 2). And centripetal aggregation type of layout patterns can be very good to change this phenomenon, the centripetal aggregation of space by building spatial organization form of centripetal heuristic, or dot shape, or circular, in the space to set focus on the core of the tourist sight, new media art space use a line with the center content together to lead the tourists to visit the path and psychology to allude, open mind, Form a good atmosphere of mutual participation and sharing.According to the different characteristics of the exhibition form and the information content of the key exhibits, the centripetal exhibition space layout with the intervention of new media art can be divided into point-level aggregation layout or circular aggregation layout[10].
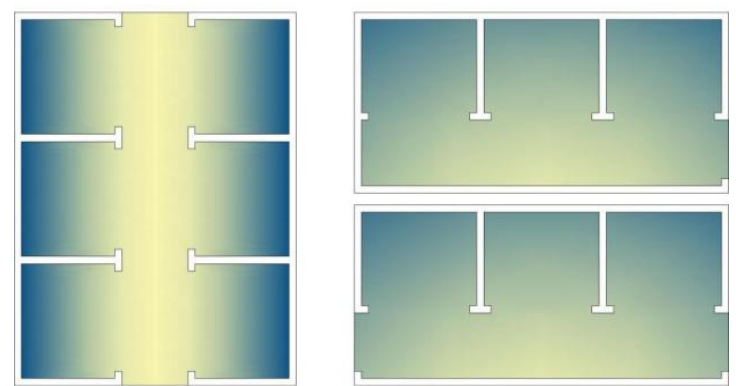

Fig 2. The traditional "partitioned" exhibition space layout leads to the lack of participation of tourists

(1) Point layer aggregation layout

Point-level convergent layout refers to the spatial function of directly changing the location of the central point by creating a rich sense of spatial hierarchy through creating different vertical heights or fitting Spaces and other interface transformation methods. On the basis of its core display function, it is endowed with the function of gathering clear spatial boundaries. The core location does not participate in the tourists' visiting moving line, giving tourists an opportunity to gather and experience the core static space.If the display information is presented in the core static space in the form of new media art, such as digital video playback, naked eye 3D projection and other forms of information 
expression, it will greatly improve the resident and gathering effect of tourists in the central location, and bring down the communication psychology of tourists in the implicit suggestion of space, thus generating natural interaction and discussion.

Convergent point layer on the plane layout style has strong field properties, highly promoted or the location of a gathering at the center of the ground subsidence, or direct WeiDang build rich spatial hierarchy, because space at a subject function partition and clear organization of tourist guide suggests that ensure that both public properties, distinct, layout is clear and orderly accumulation and dispersion, Show clear priorities of information.

Kengo Kuma \& Associates, in collaboration with Cornelius+ Voge and MASU Planning, won the 2016 tender for Hans Andersen in Odense, Denmark Christian Andersen reconstructed the museum exhibition space by constructing circular Spaces of different sizes and making the garden ground sink and the top raise to divide the spatial levels, forming a multi-point level convergence layout.Each layout space is equipped with a theme of Hans Christian Andersen's fairy tale, which is presented in the form of various new media art in the central gathering place.In this way, the theme of each divided space exhibition hall in the museum is not only clarified, but also allows tourists to gather in the central theme location under the "guidance" of the enclosed curved shape, and jointly appreciate and experience the performance art in the form of new media exhibition (Figure 3).[11].

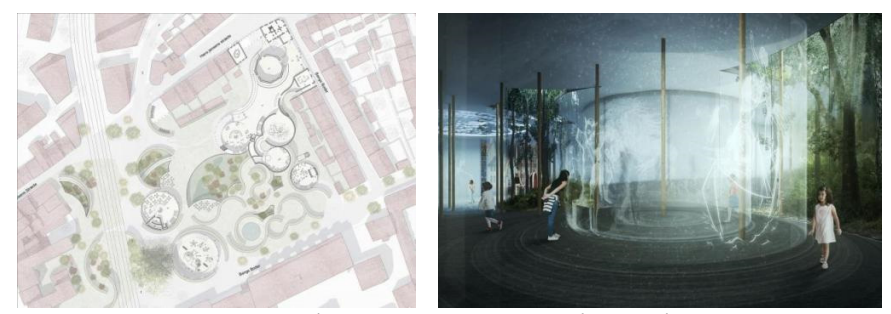

Fig 3. Andersen Museum in Odense

(2) circular polymerization layout

Circular convergent layout refers to the use of new media art form ZhanChen centring on the basis of space has including the center space of two or more than two and a half open closed circle space organization mode, to guide visitors will follow the annular region circulation "around the island type" gathering activities, so often used in the core content rich details or size large ZhanChen space[12].Compared with the point-level convergence layout, the circular convergence layout is characterized by the prolonged collision of visitors' sight line and the further clarification of visiting streamline. The extended line of sight means a wider perspective, which can not only observe the contents of the exhibition more comprehensively and carefully with the movement around, but also observe the feedback and expression of the other tourists on the contents of the exhibition on the other sides. The visual centripetal collision between each other forms a social centripetal space, which is easier to stimulate resonance and discussion.At the same time, the annular layout of multiple circles brings a higher volume ratio of small space, which is more for the audience. With each additional circle, there is more space for the classification and arrangement of exhibits. The more comprehensive the display content, the stronger the sense of public space.

Similarly, zaha Hadid Architects has designed the Science Museum's Mathematics Gallery, suspended above the centre of the space is the Handley Page "Guganook" aircraft, which was built in 1929 as part of the Safe Aircraft Design Competition, surrounded by a new media art installation that echoes it. It is based on the calculated air streamline during the flight of the aircraft as the outline concept design streamline interface, and mathematical development to promote the development of technology linked to the theme of the exhibition[13].At the top of the organization to extend from smallpox to ground the layout some narrow surface layers for half open envelopes, large dimension from the center position of the core content is the plane + streamline device shows around radioactive arrangement of secondary structure, such as booth, chairs, and suspended in the air pod shape surface device, etc., added up the space to show a complete circle.Visitors will first be impressed by the 
dynamic air flow form of the core display, and feel the connection between mathematics and every aspect of life at a glance. Then, they will operate the surrounding interactive devices around the island and explore the deeper contents of the display (Figure 4).
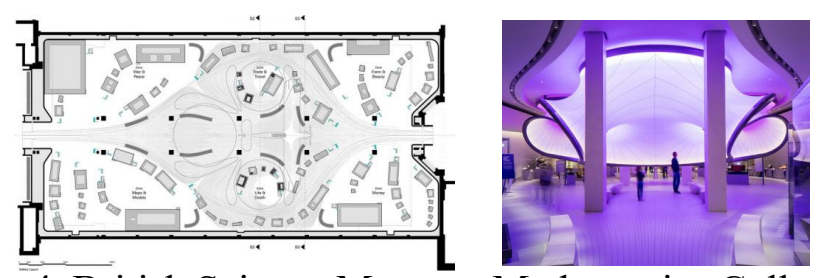

Fig 4. British Science Museum Mathematics Gallery

\subsubsection{Build a Three-dimensional Layout with Three-dimensional Extension}

Due to the limitation of backward construction engineering technology, inconvenient mobility of large-scale exhibits and the pursuit of the highest cost performance of comprehensive economy, the traditional museum museum exhibition space is generally designed as a single-storey layout with high floors. Tourists are always in the same plane with the exhibits, and can only visit the exhibits in a 360 degree circular way at most. The single-storey space cannot satisfy the experience of viewing from the height up or down.

After the introduction of the exhibition form of new media art into the exhibition of museums, the complexity of digital devices and the detailed characteristics of presenting information usually have a greater demand on the volume of space because of the information content and display volume for the majority of people in order to achieve interaction and sharing.At this time, designers began to shift their vision from two-dimensional plane to Three-dimensional Three-dimensional, and the vertical storey and high-rise space began to be fully displayed and utilized[14]. At the same time, it can also provide tourists with a panoramic view of 540 or even 720 degrees, increase the number of spaces for tourists, and achieve a positive cost performance increase in terms of income generation and publicity creation. Therefore, the spatial expansion of core show location and extended upward can not only follow the rationality of the layout theme specifications, and than at the top of the ground subsidence make model means of rich space level, build up extended Three-dimensional layout can be more convenient to implement dividing space hierarchy, the purpose of the functional properties and with additional public space [15]. Multi-angle browsing and visiting can let tourists of different levels "change layers to change scenery", more meaningful into the immersive charm of new media art exhibition. According to the summary of the case study, the Three-dimensional extension and Three-dimensional exhibition space layout under the intervention of new media art is usually achieved through two construction methods of extension and placement of upward ramps or additional arrangement of multi-layer platforms.

(1) Extend into the upward ramp

The extension into the upward ramp means that the museum exhibition space is inserted into the Three-dimensional winding and extending up ramp filling Three-dimensional layout on the basis of the single-layer layout.This kind of ramp ladder is different from the orderly connection of the plane level parallel to the ground, but more tends to climb around disorderly with the spatial boundary and the trend of the exhibition form, and the ramp always has a certain tilt Angle with the platform or the ground.

For example, MVRDV2015's midyear project, The Rotterdam Bojmans Van Beningen Mirror Museum, uses Three-dimensional geometric ramps to create a Three-dimensional functional space that integrates maintenance, display, storage and transportation.Exhibits the particularity of the case is the collection and ramp around the location of the swap, not near the center of the core show scene but ramp up, although the sacrifice ZhanChen content of primary and secondary, respectively, but makes on both sides of the display content increased significantly, and but according to the museum of art storage location, storage protection than the display function, So this kind of embedded ramp makes sense.At the same time, the extended upward Three-dimensional layout for different levels of 
tourists in the possibility of communication and interaction, participating artists can get visitors to the exhibition feedback and understanding, also be able to get the comments and Suggestions for other artists, tourists can learn more to compare, also experienced each positioning crowd of space activities (Figure 5) [16].

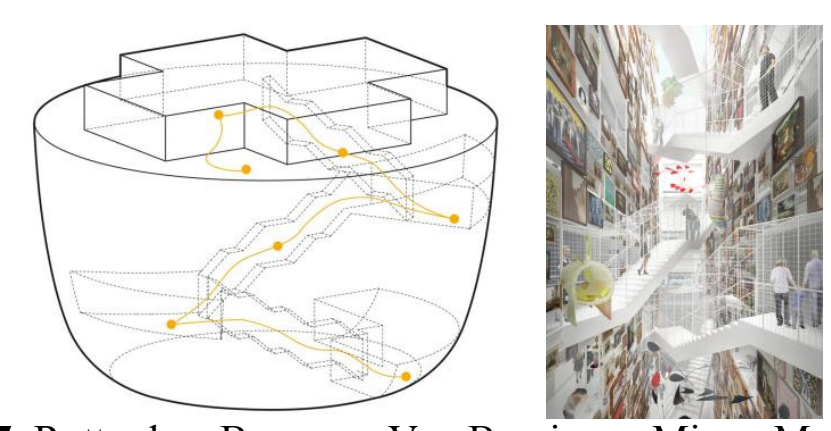

Fig 5. Rotterdam Boymans Van Berningen Mirror Museum

(2) additional layout of multi-layer platform

The method of adding multi-layer platform refers to adding roundabout viewing platform in the space above the core display location or cutting the Three-dimensional space effect of atrium skylight above the core display location in multi-layer space[17].The biggest advantage of adding a multilayer platform lies in the full development of the facade space, which directly doubles the activity space area and the duration of visitors' stay and appreciation, and maximizes the difference and separation of spatial levels. Through bottom-up circulation, visitors can get different experiences at different levels and share and respond to each other at the same level and different vertical heights. The focus of 540 degrees or even 720 degrees will further enhance the core representative status of the exhibition content.

Similarly, Studio Gang's concept for the educational innovation extension of the American Museum of Natural History in New York City creates a seven-story atrium in the central lobby, Concrete is used as the building material to simulate irregular forms in nature such as karst caves, mountains, valleys, rivers and glaciers as "geographical centers".[18].The irregular walls form a bottom-up multi-layered irregular circular platform, while suspended in the center are derived biological models of the earth's various ages. Visitors can enjoy the creatures of the corresponding era at different levels at the same time, and feel the ruggedness of natural works and the beautiful music of biological evolution.Similarly, in terms of lighting, the "embedded" atrium space introduces a larger area of skylight lighting at the top of the space, resulting in greater brightness and natural charm (Figure. 6).
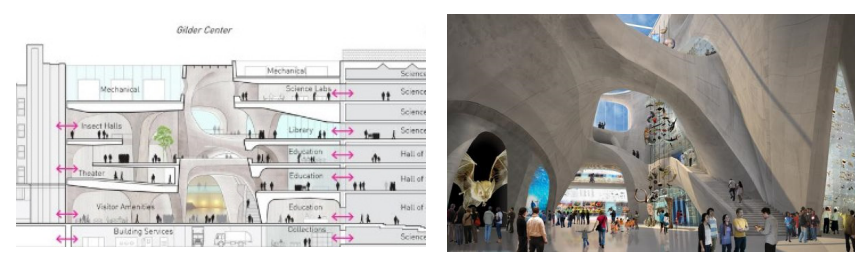

Fig 6. American Museum of Natural History

\subsubsection{Build a Non-linear Open Layout}

As a representative of Gestalt psychology in the later period, German-American psychologist Kurt Lewin mentioned the concept of "mental life space" in his published theory of psychological dynamic field [19].Gestalt psychology believes that human behavior is the manifestation of psychological action. He summarizes the relationship between human behavior and the formula of the spatial environment as follows:

$$
B=\mathrm{f}(P E)
$$


B refers to people's behavior, P refers to people, E refers to people's perception factor of the site environment, and $\mathrm{F}$ refers to the function law. This formula indicates that people's behavior will change with the change of people and the environment. When the environment has strong binding force on people, people's activities will have certain unity and coherence; when the environment has weak feedback on people, people will have different personalized behavior, with strong subjectivity and disorder.

Traditional museums mainly display physical exhibits, and the historical origins and background stories behind exhibits are often unknown to people. Therefore, a narrative tour with strong guidance and closely related plots is needed to ensure that visitors can solve the obstacle of understanding the information of exhibits. Therefore, on the basis of the "partition" plane layout, the traditional museum exhibition space usually sets up a coherent time line to create a narrative novel-like visiting rhythm and explain the plots of the characters behind the exhibits in turn, thus forming a linear streamline with strong spatial initiative (Figure. 7).

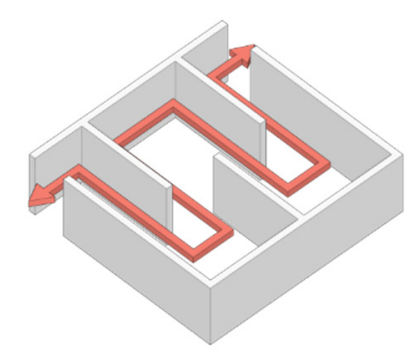

Fig 7. The linear streamline of the traditional "partitioned" exhibition space

Although narrative spatial organization streamline does have certain rationality and stability for visitors' information intake about exhibition activities, excellent organized story presentation can achieve interesting and fascinating psychological output effect and ensure the effective transmission and reception of exhibition information.However, the unified and qualitative visiting streamline model excludes tourists' subjectivity, abandoners their freedom in the process of visiting, and makes them only passively accept the standardized experience.

When new media art in the museum after ZhanChen activities, especially large image type media art forms across time and space performance characteristics, exhibits scrolling background information can be shown directly in any interface, dynamic image contains huge amount of information and vivid image, no longer need a fixed linear visit streamline to into the narrative.And new media art has rich elements and overall stimulation of the sensory perception to tourists planning a wealth of experience, each visitors can freely according to their concerns and interests take the initiative to obtain relevant information to the plot, provide the excavation of the tourists exploratory and liberation consciousness, aware rejection has nothing to do boring things, respect for individual of the play, To get the best immersive enjoyment [20]. Therefore, in the exhibition space design of new media art forms, linear space guidance can be appropriately reduced to weaken the space hindrance to tourists, and nonlinear open layout can be adopted to deconstruct the separated space organization and create roaming space for tourists to pay attention to their exclusive areas.

(1) Set disperse streamline

The Non-linear open layout is usually a plane deconstruction of the wall interface organization, without specific entrance and exit of the exhibition hall, resulting in a combination of multiple visiting lines.At the same time, the deconstruction of the plane layout is not random cutting without chapters, but to make each wall organization interwoven and scattered, the entrance is closed, forming the unity of the overall direction of the exhibition hall and the dispersion of the display sequence.Tourists can visit in after a exhibits the be fond of according to topic or forms tend to choose the direction to the next place, every tourist visit move line organization together is one unique path roaming, exhibition party through summarizing different characteristics of the crowd of path rule can provide a variety of visitors to see their path to different concerns for your reference, more in line with the human. 
For example, the Austrian Pavilion of the 2020 Dubai World Expo, which was successfully awarded by Querkraft, has a typical Non-linear open layout by setting decentralized circulation lines. Throughout the exhibition hall, the arrangement and combination of a number of cones with the top cut off and the bottom cut off are interspersed to form a complete open roaming space. The openings of each cone are used to form a number of scattered channels so that visitors can walk through them at will and read the story language presented by the light from the sky on the wall (Figure 8).

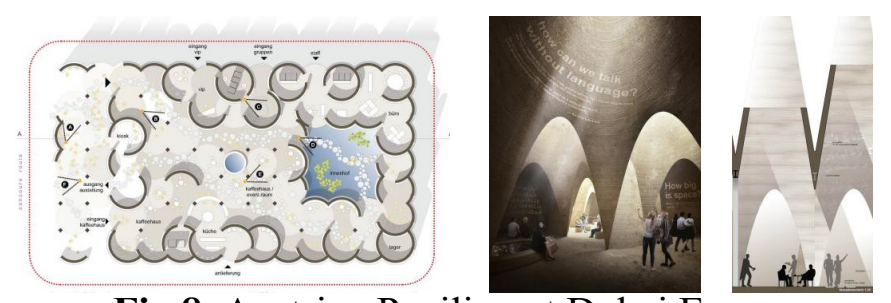

Fig 8. Austrian Pavilion at Dubai Expo

(2) Prohibition of enclosing borders

In addition, when there are many elements involved in the form of new media art, or when exhibition installations and space are assimilated into each other, a Non-linear open layout can be built by directly eliminating the enclosed boundary of indoor exhibition space. Eliminating enclosing boundaries is completely useless and unordered blank space compared to setting the layout mode of scattered streamlines.

For example, there is no obvious partition or identification channel in each theme exhibition hall of Shanghai teamLab Unbounded Art Museum, and a single penetrating screen is arranged in each direction to create a fully immersive interactive exhibition hall. The light particles presented by digital technology and the surround-type holographic projection screen are used to assimilate the whole space. It has a precise optical structure inside, and has the function of presenting real scene and image simultaneously, which is both inside and outside of the space boundary. The display style can show the dynamic interaction effect with the tourists as they walk around. The tourists can plan their own visiting route independently according to the feedback of the images around them by unconsciously and aimlessly roaming in the space.Just as the theme of the design of the pavilion: there is no boundary between the works and the same immediacy as the visitors, the visitors establish a connection with the space, establish a relationship with others, explore the boundary with their mind and body, and communicate across the boundary (Figure 9).

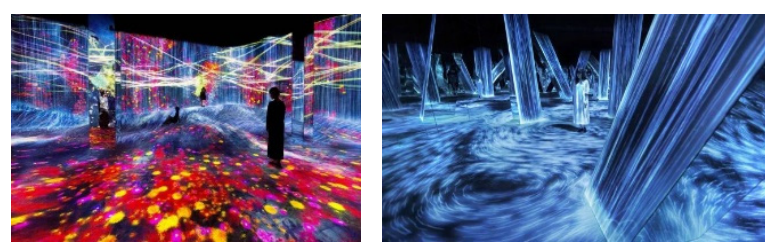

Fig 9. Shanghai team Lab Art Museum

\subsection{Details of the Flexible Space Shape Adapted to the Exhibition}

With the introduction of new media art in exhibition activities, the original physical display began to change into a variety of media information output, space and exhibits are no longer confined to the simple and rigid physical placement relationship, and begin to develop in the direction of mutual agreement and complement each other.Details about ZhanChen space, therefore, display the form of design consideration, to get rid of the previous theory of style, combined with the feature of the number of new media art and interactive features, hard outfit form interface to have enough flexibility to serve the mercurial ZhanChen form, shape supporting form interface shape, increase the space with each detail ZhanChen ZhanChen fit, in the form of building with digital display digest, The natural pure digital form space achieves a more futuristic, experiential and detached visiting and exhibition effect. 


\subsubsection{Meet the Requirements of Node Devices}

In the forms of new media art exhibition layout, are generally change ZhanChen forms of external form to joint space form, this is because the new media art ZhanChen brake is smaller core device and display interface or av interface are generally not removable removable, so exhibits arrangement on the decision making usually has a lot of compromising and flexibility.However, there are also many permanent exhibits or fixed display devices with certain particularity, unable to carry out the configuration of late form allocation or temporary increase of optical power grid, or temporary arrangement appears mechanically rigid, and space style violation. Therefore, in this case, in the early stage of space construction, it is necessary to take into account the needs of point location and routing, etc., and the shape shaping of the display device part should realize flexible transformation and integration by borrowing unconventional node practices such as customized keel or steel frame to meet the display needs of node devices, and successfully show the best display effect [21].

According to multiple cases concluded that, at present it is necessary to take into account into the early stage of the design space form of new media device is mainly screen projection system, such as ball screen dome projection, annulus arc screen projection screen projection, folding screen bowl and so on, these special laying projection imaging devices need space form, adaptation and joint, therefore the spherical museum buildings or surface. The application of these projection technologies in the museum exhibition space aims to use the fisheye imaging lens inside the projection machine to project a picture beyond the visual field of human eyes to the curved screen, which is similar to THE 3D mapping of HDRI, so as to give visitors a more realistic immersion feeling (Figure 10). Therefore, the internal form of the exhibition space needs to be prepared for the later placement of these curved screens to create a unified Angle of wall sky, wall body and wall ground interface.

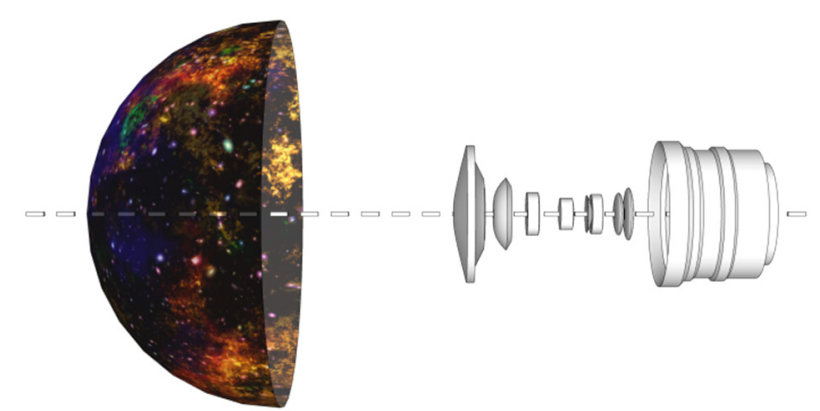

Fig 10. Schematic diagram of curved surface projection imaging structure

Although the projection devices required by some new media art effects limit the spatial shapes of local nodes, the screens, whether spherical, partial curved or faceted, are all unconventional hardmounted models, which tend to be active and convex in the whole space.If the effective space organization can be combined to distinguish the primary and secondary links and shape the wall shape echoing each other, a good spatial order and rich spatial levels can also be created [22].

For example, in 2015, Shift Architecture Urbanism designed the Astro-themed theater at the Limburg Museum in The town of Kelklade. The two spheres, 16 meters wide and 9 meters deep, have a domed upper hemisphere that plays national Geographic movies and documentaries. Part of the lower hemisphere is the Earth Theater, which shows the process of astronauts returning to the Earth, with circular audience seats on both sides [23]. the novel concept of "Flipping heaven and Earth" enables visitors to experience an immersive return from space as if they were floating in space beyond the Earth.

The boundary shape of the whole top and bottom is unified with the metal panels outside the main body of the building to achieve a perfect match between the two ball screens to display the boundary.It also makes part of the exhibition hall become the focal point of the whole museum building. The infinite global projection effect is shocking and spectacular, and becomes the visual focus of visitors inside the museum. The sphere shape of the exterior is also in obvious contrast with the surrounding 
Volume 14 (2021)

buildings, simple and unique. The dynamic temperament of the landscape architecture can arouse the curiosity of tourists outside the building to peep into the sphere exhibition hall inside (Figure 11).

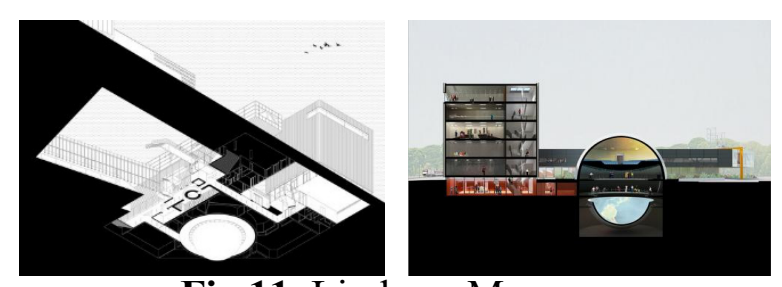

Fig 11. Limburg Museum

\subsubsection{Turning Point of Activated Body Wall}

According to the above research, the physical display method in the traditional museum exhibition space isolates the relationship between exhibits and space, which simply belongs to the relationship between container and content. The actual display effect of exhibits only depends on its own form and particularity, and has nothing to do with the hard-mounted form of the space. The traditional design concept of museum exhibition space does not include the consideration of shape transition and display effect.However, any material relying on visual transmission of information needs corresponding display interface to record information content, and different types of information content even have their own adaptation requirements for interface shape transition or physical material properties.

In the exhibition activities involving new media art, most involve image-like digital screen interface and interactive operation panel interface [24]. Often contain the class information bearing interface elements in a wide range of information content, size and shape, need appropriate reasonable arrangement of the collocation of feed into space, usually attached joint at space boundary wall recessed embedded operation, so that we can hide the line switch, and does not occupy space, realize simple display. Therefore, the turning trend design of the spatial form interface should take into account in advance the requirements of the outline, area and shape of the new media art information presentation interface matching the display content.

Human eyes in the sky have better adaptability and immersion for enclosing the picture without boundary.In the context of spatial form interface bearing information, once the form is turned and distorted, the different intensity of reflection of ambient light received by human eyes will lead to the different brightness and color difference of the information display interface, resulting in the temporary interruption of the effective transmission of information and the coherent appreciation of visitors. Therefore, it is the most appropriate to shape a continuous and smooth corner wall when the form interface is required to carry information, which can effectively reduce the visual experience of visitors and improve the display effect of exhibits information.

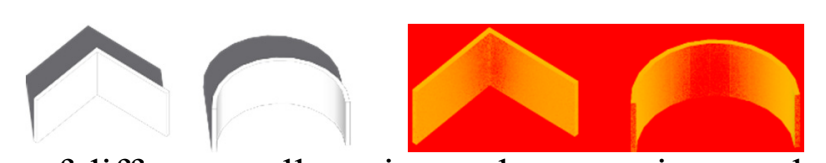

Fig 12. The influence of different wall turning at the same time on the irradiance of light

(1) The application of simple arc surface

The application of simple curved surface refers to the continuous curved space form which is simply organized and connected by curved surfaces of different radius and length.Compared with the rigid angular form in the traditional exhibition space, the curved space form can achieve a softer transition of reflected light, and has less influence on the presentation of the contents displayed on the interface.In addition, the circular continuous wrapping interface conforms to the law of human visual field and distance, that is, it completely covers 180 degrees of parallel visual field with the same distance. Tourists can absorb more information elements on the interface filled with complete line of sight.Secondly, the enclosed direction of curved surface can provide tourists with stronger 
psychological hints, give them a sense of belonging and privacy, and help them to enter the experience state faster.

The Patricia and Phillip Frost Museum of Science in Miami, designed by Grimshaw Architects in 2017, In both the aquarium and the dome, a simple curved surface is used to enclose the body boundary [25].The single flexible surface eliminates the stiffness of the transition of the conventional body, forming a smooth and closed complete display interface. Supporting the form of new media display to enhance the continuity of the lens and achieve more realistic visual enjoyment (Figure. 13).
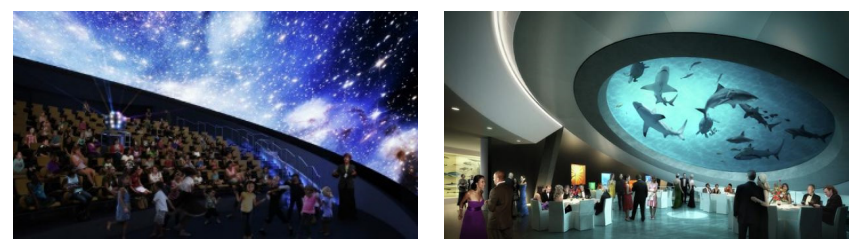

Fig 13. Patricia and Phillip Frost Museum of Science

(2) The application of complex abnormals

Different from the simple curved surface as a continuous information bearing interface in the space, the application of complex special-shaped interface in the museum exhibition space is usually to create the space itself as a new media art exhibit with the participation of digital technology or to interpret the space as an external form of the idea of the exhibit.The development and popularity of the special-shaped interface benefits from the progress of NUMERICAL control processing technology and the application of topology in environmental design and the evolution of parameterization. Topology catalyzes the theory of manifold, distortion and fold in interior interface design.Random relation functions generated based on topological deformation are applied in software programs in related architectural fields. Efficient model fragmentation and model iteration methods are used in the process of scheme construction to realize bending, smoothing, gradual change, lattice, melting and other forms of deformation of spatial forms (Figure. 14). Through these editing methods, the hard boundary of space can be melted to become a whole complex alien form, and the form of space can be nonlinear activated to build maximum spatial continuity, ductility and levelness in an environment with no limited boundary.In addition, the aesthetic trend of complex heteromorphism conforms to people's general aesthetic imagination of space structure for future products, which can bring tourists concrete science fiction experience and stimulate their imagination.

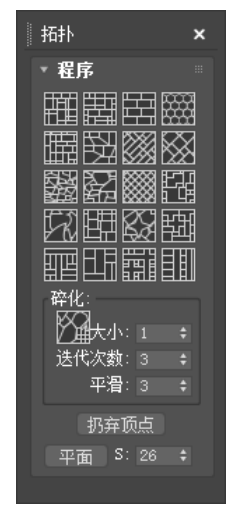

Fig 14. Topology deformation commands of environmental design software

NOX, for example, in 2000 the Netherlands digital pioneer architects designed for Hanover expo pavilions of the Dutch pavilion water, designers follow "infinite (up)" topology to find form to create a borderless and vertical turning the whole dynamic space, the space form is more clever and lightness, and install a series of interactive sensing devices within the building, It can capture the behavior of the tourists and give the corresponding sound and light feedback, which makes the tourists feel as if walking in the underwater world, which is spectacular. Through the water flow simulation of the 
activated body and the situational interactive media simulation of the water body, tourists can realize the double immersion of visual and auditory perception.In this case, according to a series of deformation final shape and topology space form by means of new media technology, its itself is the core of the exhibition display, any flow, winding form surface are all a hotchpotch of display interface, building surface texture, texture and color are all exhibits presents the connotation of external source shelter in nature (Figure 15).

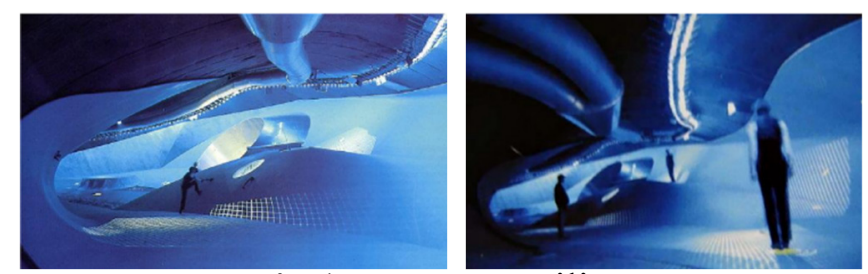

Fig 15. Water Pavilion

\subsubsection{Promote the Integration of Space Devices}

After contemporary new media art has been gradually involved in museum exhibition activities, the human-centered experiential characteristics and interactive characteristics of new media art have been brought into the design attributes of museum exhibition space. Therefore, exhibition space has begun to assimilate with exhibition installation and then transformed into a "live" exhibition installation. The installation structure of new media art began to expand into the interior of the whole space, and simultaneously injected the design concept and connotation of the installation into the space as the spatial presentation of the exhibition theme.The spatial development of the installation can allow visitors to enter the interior to obtain more convenient and intuitive interaction and feelings, and the role of tourists in the exhibition activities is also changed from third-person observer to firstperson participant (Figure 16).

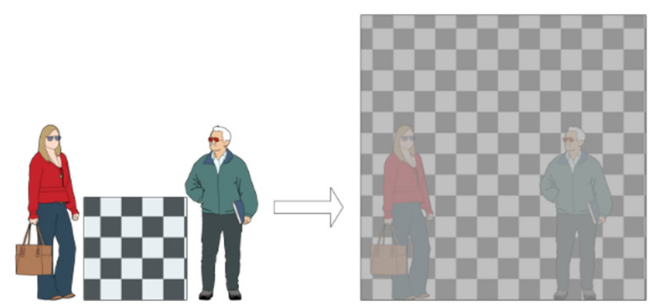

Fig 16. The spatial transformation of exhibition activities

The harmony and symbiosis of space and installation not only retains the physical properties of exhibition space, that is, to accommodate tourists and provide information display interface, but also has the digital properties of new media device, which saves the occupation area of exhibition content in space and eliminates tourists' sense of constraint and path restriction in visiting behavior. To provide maximum space and maximum scale of free communication between tourists and display contents, tourists and tourists.According to the summary of relevant cases, there are generally two processing modes for the space shape shaping that can be achieved in harmony with the device, namely, integration of the whole space and local interface bonding[26].

(1) The overall space is integrated with the device

Integral space harmony refers to the hard outfit at the beginning of construction, the working principle of the reasonable reference ZhanChen device selects a series of new type building material, the structure of the implementation of the corresponding measure, embedded digital intelligent means, etc., covering space within every form interface, "imitation" and ZhanChen device the same function and concept of integral space, form a "space is like" display environment. This integration of space and installation is often applied to temporary, mobile exhibition Spaces or small, independent galleries due to cost and technology constraints.On the external level, the space form is endowed with more ductility and material properties, which can construct flexible and diverse styles and forms, 
achieve rich and innovative functions, enhance the sensory perception experience of tourists, and expand the cognitive level of tourists.Visitors' movement in the space is always receiving the transmission of the display content information, and the information hidden in the space is rich, delicate and impressive.

For example, the future Exhibition Hall of Hisense Science Exploration Center, designed by Naked Renewal Architects in 2019, follows the design concept of "space as image" and takes the whole space as the carrier of display content and metaphor of theme.The designer extracted the "spectrum screen", the core highlight of Hisense products, as a design element, and expanded its fuzzy to clear progressive features to the whole spatial scale. The designer intends to transform the overall interface of the space into a single theme exhibit, whose central theme is the order in chaos, that is, the physical order outside the once industrial TV has evolved into the electronic disorder inside the modern LCD TV.In order to show this kind of view, the light penetration $5 \mathrm{~mm}$ sunshine board is integrated on the top and wall of the entire space, and the color-changing lamp belt and weak current control are installed to simulate the invention principle of the spectrum screen, so as to create a sense of spatial order in the transition between cold and warm light, and realize the synchronous display effect of all the TELEVISIONS on the wall and the space as exhibits.In this case, the overall space is integrated with the special installation, and as an independent exhibit, it is endowed with brand connotation and scientific significance, so as to realize the creation of spatial views and output spatial views to the audience participating in the whole space interface effect [27].At the same time, this integrated installation assimilation space belongs to a new media art work, which also conforms to the conceptual and interactive characteristics of new media art works. The shaping of space forms presents the aesthetic height of futurism and contains profound ideological depth (Figure 17).[28].

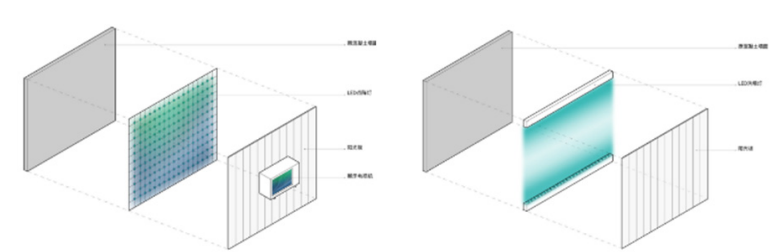

Fig 17. Analysis of the effect of "light filtration" on the wall surface of the sun panel

(2) Local interface is bonded with the device

Local interface and device bonding refers to the practice of integrating the local space and the device with the new media art installation built into the space cavity, which is close to the interface or glued to the top surface, so as to cut a space in the overall space to create local location of the installation or small space of the device[29].It mainly serves as a supplement to the overall space presentation effect and an interesting node to enhance the experience. At the same time, according to the structure of the space shape, or the icing on the icing type as the extension and tension performance of the body, rich interface level change and structural form, or the deficiency as the body supplement and defect cover, repair the structural problems and functional improvement of the interface.
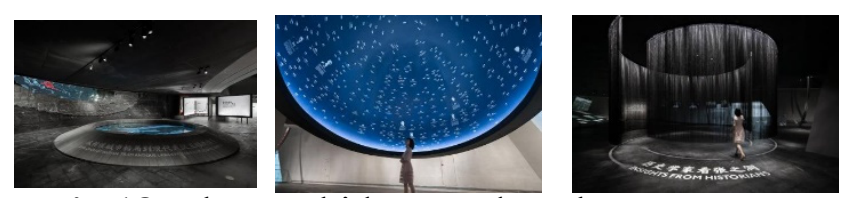

Fig 18. Zhang Zhidong and Wuhan Museum

For example, built in 2014, Zhang Zhidong and Wuhan museum, stylist in multiple local node position use design methods such as joint, hollowing out, interspersed with set image device, from large integral space of independent multiple private experience device space, such as Zhang Zhidong, a think-tank, space, from traditional pattern to the modern evolution of the three towns of Wuhan city experience, such as space, The unique shapes protruding from the existing space are presented as 
tension in the silent space and also as devices with different functional directions, allowing visitors to experience the conflict between history and present times (Figure 18).

\subsection{Set up a Comprehensive Range of Scientific Space Suitable for Exhibition}

The setting and division of the scale range of each indoor functional area is an important part of the preliminary design of space [30]. With the application of new media art in exhibition activities and exhibition space design, the digital technology at its core leads the transformation of exhibition forms and visitors' exhibition forms, and exhibition activities begin to transform into space (Figure 19). Thus, the division and setting of exhibition space design also brings new measurement standards.Will launch new media art scale information in early space scope inside ZhanChen activities planned comprehensive considerations, ZhanChen space scale and contains exhibits ZhanChen scope and visitors to the exhibition activities in harmony harmony, realize the scientific scope of macro regulation and control, there will be no space already so wasted resources, It will not lead to insufficient exhibition areas and poor perception of visitors[31]. Therefore, adopting the specific means of new media art elements and taking comprehensive consideration to set the scientific space scope suitable for exhibition is the basis of the overall "shape" design, which is divided into the control of basic scope, perception scope and activity scope [32].

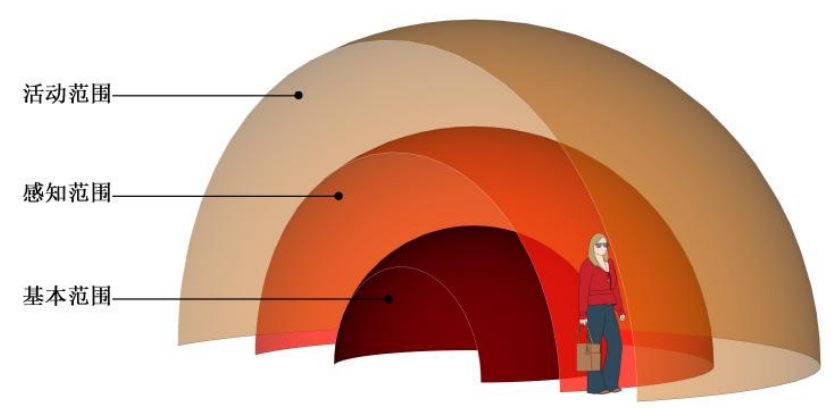

Fig 19. The spatial transformation of exhibition activities

\section{Conclusion}

Combined with practical cases, this paper studies the technique of hard installation of "form" in the case of new media art intervening in museum exhibition space, and narrates it from three aspects of spatial layout, spatial form and spatial scope. First of all, in terms of spatial layout, it constructs the plane layout of centripetal gathering, Three-dimensional extension, nonlinear open layout and Three-dimensional conscious layout to promote the audience's participation behavior.Secondly, in terms of space form, it is required that the form interface meet the needs of node device, activate the turning of the form wall as far as possible, promote the integration of space devices, and achieve the perfect adaptation of new media art form and space through these three ways. Finally, following the concept of scope in the form of new media art, the scientific specification of the scope of museum exhibition space is upgraded, and the allocation of space is comprehensively regulated according to the three concepts of basic scope, perception scope and activity scope, so as to improve the level of tourists' experience.

As a cultural place with the property of information transmission, the development of the design concept of museum is bound to be affected by the change of the form of information media. As the new media art forms of exhibition activities become the mainstream of The Times, museum exhibition space design should also produce certain changes to support the new display forms. 


\section{References}

[1] Li Zhi. Research on the application of virtual reality technology in digital Museum [D]. Chongqing University, 2017.

[2] Pan yameng. Research on the application of new media technology in museum exhibitions [J]. Science and technology communication, 2018,10 (15) : 137-138.

[3] Cheng Xiandong. Virtual and Reality [D]. Central Academy of Fine Arts, 2011.

[4] Ma Ke. Research on media Value of media architecture [D]. Huazhong University of Science and Technology, 2017.

[5] Road trip. The multimedia version of visual shock qingming scroll [EB/OL]. (2017-09-02) [2020-05-18]. https://www.sohu.com/a/168592751_808293.

[6] Tencent expo. Germany pavilion "ball of energy" perfect interaction with the audience [EB/OL]. (201005-05) [2020-05-18]. https://2010.qq.com/a/20100505/000286_1.htm.

[7] STONESDESIGNLab. Museum of Zhang Zhidong in Wuhan [EB/OL]. (2017-11)[2020-05-18]. https:// www. stones design. net/Museum-of-Zhang-Zhidong-in-Wuhan.

[8] Vimeo.THETREASURE-EXPO2010SHANGHAI[EB/OL]. (2010-10-07)[2020-05-18]. https:// vimeo. Com/ 15629513.

[9] GuDe design network. 2019 world horticultural exposition in Beijing plant pavilion [EB/OL]. (2019-0819) [2020-05-18]. https://www.gooood.cn/botanic-garden-for-international-horticultu ral-exhibition-20 19-china-by-urbanus.htm.

[10] Designboom. Teamlabfillsformeroiltankswith 'digitaluniverseofwaterparticles inshanghai [EB/OL]. (2019-03-22) [2020-05-18]. HTTP ps://www.designboom.com/art/teamlab-universe-of-water-particlestank-shanghai-03-22-2019/.

[11] Designboom.Coordinationasia:shanghaifilmmuseumlinkspastandfuture[EB/OL].(2013-07-02)[2020-0518].https://www.designboom. com/architecture/coordination-asia-shanghai-film-museum-links-past-and -future/.

[12] Yang Wenchao. Research and Application of Human-computer Interaction Technology for Personal Experience [D]. Southwest University of Science and Technology, 2017: i.

[13] Welovead.GalleryOne[EB/OL].[2020-05-18].http://www.welovead.com/en/works/details/e54wnuswf.

[14] Tang Linyun. Research on intensive Application of Digital Technology in Display Design [D]. Nanjing University of Aeronautics and Astronautics, 2017:10-11.

[15] Is not the same as the sensor technology. $3 \mathrm{~d}$ - hologram technology [EB/OL]. (2017-09-28) [2020-0518]. https://www.sohu.com/a/195062140_468626.

[16] Baidu experience. Projection screen: annulus cinema systems [EB/OL]. (2017-02-09) [2020-05-05]. HTTP: //https:// jingyan. baidu. com/article/ 9158e00055 fcc1a2551 2284a.html? st=2\&net_type=1\&bd page_type $=1 \&$ os $=0 \&$ rst $=$.

[17] Fire $m$ interaction. The classification of ball screen projection is introduced [EB/OL]. (2019-01-04) [202005-18]. http://www.huomi360.cn/fqiumty/aqiumty/a042495.html.

[18] Hong bo network. + VR museum, what are the new play [EB/OL]. (2019-09-30) [2020-05-06]. https:// www. sohu.com/a/344391035_426335.

[19] Yamete. Cook: VR into communication barriers, AR is the future [EB/OL]. (2017-02-09) [2020-05-05]. HTTP:// http://www.smarthey.com/Index/detail/id/4303.html.

[20] ISO. EPICIreland-AVInstallations\&Interactives [EB/OL]. [2020-05-05].http:// isodesign. co. uk/ projects /epic-ireland-av-installations-interactives.

[21] Wang Weihang. Research on Architectural Space Interactive Design of Modern Science and Technology Museum [D]. South China University of Technology, 2018:26.

[22] Scolor Designboom. Teamlab '- changingfloatingspheresinSingaporerespondtohumantouch [EB/OL]. (2017-06-01) [2020-05-18]. https:// www.designboom.com/art/teamlab-national-gallery-singaporehomogenizing-transforming-world-06-01-2017/.

[23] Zhang Caiyong. Research on design of Contemporary Multimedia Installation and Building Space Environment [D]. Chongqing University, 2008:74,85-90. 
[24] A ShaJun. Explore teamlab borderless: digital art museum in Tokyo, Japan [EB/OL]. (2018-07-25) [202005-18]. https://www.sohu.com/a/243318652_806454.

[25] Vitruvius. OsujeitofenomenologiconaarquiteturadoH2Oexpo [EB/OL]. (2010-10-11) [2020-05-18]. HTTP: // https://www.vitruvius.com.br/revi Stas/read/arquitextos / 11.125/3541.

[26] GuDe web designs. The 2012 yeosu world expo industrial pavilion South Korea's hyundai group [EB/OL]. (2013-09-17) [2020-05-18]. https://www.gooood.cn/hyundai-pavilion-by-unsangdong.htm.

[27] Ma Yuan. Research on the impact of interactive experience on exhibition space environment [D]. Shandong Jianzhu University, 2017:45.

[28] Architectural engineering. Denmark Horizon [EB/OL]. [2020-05-01]. http:// www. architectural engineering. dk/en/cases/expo-2012.as px.

[29] Vimeo.VISUALSYMPHONYBMWMUSEUM2008[EB/OL]. (2011-12-01) [2020-05-18]. https://vimeo. Com/32968176.

[30] Ju Yexin. Research on Cultural Consumption and Contemporary Museum Architectural Design Concept [D]. Harbin Institute of Technology, 2010:119.

[31] Yang Z P. Research on interactive development trend and design strategy of contemporary Art Museum [D]. South China University of Technology, 2016:56.

[32] Wang Yihan. Research on pan-visualization and aesthetic Perception of spatial Form of contemporary Western architecture [D]. Harbin Institute of Technology, 2017:44.

[33] DILLERSCOFIDIO+RENFRO.BLURBUILDINGSWISSEXPO2002[EB/OL]. (2002-05-15) [2020-0518]. https://dsrny.com/project/blur-building.

[34] Behance. SAMSUNGINNOVATIONMUSEUM [EB/OL]. (2014-07-25) [2020-05-18]. https:// www. behance. net/ gallery/18524467/SAMSUNG-INNOVAT ION-MUSEUM. 